\title{
Central Java Voters' Perceptions of Simultaneous Regional Elections 2020 during the Covid-19 Pandemic
}

\author{
Priyatno Harsasto ${ }^{1}$, Neny Marlina ${ }^{2}$, Supratiwi ${ }^{3}$ \\ \{harunosa@yahoo.com ${ }^{1}$ \} \\ Universitas Diponegoro, Indonesia ${ }^{1,2,3}$
}

\begin{abstract}
This study analyzes people's perceptions of the 2020 simultaneous elections in Central Java. Many cases show that incumbents who come from the winning party of national elections often fail in disaster situations. This happens if voters' perceptions of the national handling of the pandemic are negative. This study will also look at voters' perceptions of implementing health protocols as part of the psychological protection of voters when they exercise their voting rights in a pandemic situation. The patronage democracy system implemented in Indonesia creates incentives for voters to choose candidates from the same party between elections and regional elections. However, the honeymoon period did not last long when the government was deemed unsuccessful in dealing with the pandemic.
\end{abstract}

Keywords: Pandemic, Safety, Patronage Democracy

\section{Introduction}

In the era of democracy, elections as a practical political practice are an important factor that can become an instrument of public control over the authorities. Elections give birth to political leaders and parties that carry out the mandate for the welfare of their people and also serve as filters for leaders based on certain preferences of voters. Direct local election (Pilkada) has been held since 2005 and has resulted in a new political culture in the process of regional leadership rotation. Through this direct election mechanism, the public is educated to interpret the regional head election process by going through a contestation process which makes losing and winning must be accepted gracefully. The regional election process that has been carried out procedurally has also gone through a democratic, free, fair and non-violent election mechanism. Therefore, the people are actually very accustomed to and understand how to respond to a democratic event in the regions which has been regularly held every 5 years.

Originally 2020 elections will be held on Sept. 23 to elect nine governors, 224 regents, and 37 mayors simultaneously. The 2020 Pilkada will be different from other Pilkada because this Pilkada is held during a pandemic. The implementation of the Pilkada at each stage risks the occurrence of contact between people who have the potential for Covid-19 transmission. However, the government remains unmoved, through Perppu No. 2 of 2020 the simultaneous local and regional elections will be held on December 9, 2020.

The General Election Commission (KPU) has carried out a series of stages for the 2020 simultaneous local and regional elections. However, due to the Covid-19 pandemic, the KPU has finally issued a KPU decree Number: 179/PL.02-kpt/01/KPU/III/2020, which among 
others regulates the postponement of several stages of the 2020's Pilkada, including the inauguration and tenure of the Voting Committee (PPS), verification of the support requirements of individual candidates, the formation of a Voter Data Update Officer (PPDP) and the voters' data updating process, as well as updating and compiling voter lists. The postponement of several stages of the aforementioned Pilkada can have various impacts in its implementation, both positive and negative. The positive impact, for example, this delay provides space for independent candidates to prepare support requirements as individual candidates. Political parties can also experience relatively relaxation in the recruitment process for local and regional head candidates. However, the positive impact is not too significant considering that the deadline for changing the implementation schedule is only three months, from 23 September to 9 December 2020. This change in schedule is considered problematic considering that the increase in the number of positive cases of Covid-19 has not slipped yet. Many experts argue that the local and regional elections during the pandemic era is too risky not only to the principles of democracy but also to the lives of voters, election organizers, security officers and even political actors who compete on this stage. This decision is certainly not without calculation. Covid-19 is a pandemic that has a high level of uncertainty when it will end. If the government waits until the Covid-19 Pandemic ends, of course there will be many economic and political problems that must be faced that can threaten economic and political stability. On the other hand, it would be much safer if the local and regional elections were carried out immediately when the clarity of the end of the Covid19 pandemic was already known.

The Central Java Community Perception Survey of the simultaneous local and regional elections during the Pandemic Covid-19 attempts to show a picture of perceptions, levels of understanding, attitudes and behavioral tendencies the public regarding the readiness of election participants, including the agenda for the implementation of the Pilkada using health protocols. This survey is also expected to be a measure of the level of understanding and expectations of society regarding healthy Pilkada and helping the Local Election Commission (KPUD)'s performance in an effort to realize the system of healthy elections with integrity as one of the important points of a good political recruitment strategy.

\section{Method}

This study uses descriptive quantitative research methods using surveys to collect data and information, description of public knowledge and perceptions of the implementation of a healthy and safe simultaneous local and regional election. Primary data collection uses interview method with 200 respondents. The tool used in this direct interview is a structured questionnaire which are conducted in several cities in Central Java to obtain data and information, description of public knowledge and perceptions of the implementation of a healthy and safe simultaneous local and regional 2020 election.

\section{Results and Discussion}

Research on voter behavior places leadership as one of the main variables. However, if it is controlled by party identification, it will appear that the impact of leadership is insignificant [1]. This study was conducted in Germany, which is a developed country with a 
deep-rooted political party and party system. In a transitional democracy the impact of leadership should be greater considering that political parties are not well institutionalized and often leaders who emerge in society have a big role in the establishment of political parties in the democratic transition process [2]. Healthy political parties are essential in supporting democratic stability. Political parties represent the interests of individuals and civil society in shaping government policy. The strength of a political party will be determined by the strength of its organization and the number of voters who identify with the party.

Sulistiyanto and Erb said that voters will make their choice based on the performance of the competing candidates. Incumbents who have a good performance will be re-elected, while incumbents who are not able to carry out their duties properly will lose [3]. Mietzner's research also noted that $40 \%$ of incumbents who were not re-elected were those who did not perform well in public services and committed corruption [4]. In Van Klinken's view, the electability of a leader in Indonesia also needs to be seen from the patronage relationship that occurs between leaders and voters. Van Klinken emphasized that the prediction of a political scientist who said that democracy was impossible in Indonesia was refuted by the emergence of what he called Patronage Democracy [5].

\subsection{Knowledge and Awareness of Pilkada in the Covid-19 Pandemic}

For the variable knowledge and public awareness of the simultaneous regional elections in 2020, it can be seen in three ways, namely; First, people's knowledge and interest in the Pilkada; Second, public knowledge and interest in politics in Central Java, and third, public knowledge of the elections in the Covid-19 pandemic. The answers to the survey questions related to the 3 things illustrate the level of public knowledge and awareness of their voting rights, politics in Central Java and the regional elections during the Covid-19 pandemic.

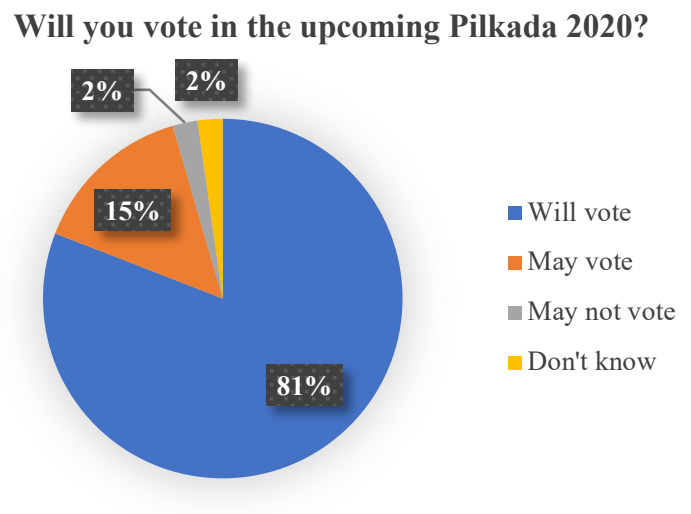

Fig. 1. Vote in the Upcoming Pilkada 2020.

The first thing to measure is their knowledge and interest in exercising their voting rights in the elections. The majority of respondents answered that they would be interested in exercising their voting rights, as many as $81 \%$ said they will vote for sure, $15 \%$ said they might use their voting rights, and only $2 \%$ stated that they might not use their voting rights in the upcoming elections. There are $2 \%$ of respondents stated that they do not know whether they will use their right to vote in the upcoming regional elections or not. This fact shows that 
information about direct regional elections which has been conducted several times periodically is no longer a new thing to the people of Central Java.

The second indicator is the knowledge and awareness of the respondent about Central Java politics. Politics in Central Java is defined as a political process in all its forms, from leaders, political actors to campaign manager (Tim Sukses). Similar to the question regarding the exercise of suffrage, respondents were also asked about their knowledge and interest in politics in Central Java. Respondents' answers support the first question about whether they will exercise their voting rights in the upcoming elections. As many as $24 \%$ of respondents stated that they were very interested, and as many as $45 \%$ stated that they were interested. So that a total of $69 \%$ of respondents followed the political process that took place in Central Java through electronic media and print media. As many as $29 \%$ of respondents said they were not very interested, and only $2 \%$ stated that they were not interested at all in Central Java politics. We can read these figures as a representation of political knowledge occurring in Central Java by the majority of respondents. They know the political process that occurs daily and show their concern about Central Java politics in general.

Another thing that was also asked of respondents was knowledge about regional elections during the Covid-19 pandemic. The questions raised were to find out the public's knowledge and also to ask for public opinion on the urgency of implementing the simultaneous regional elections during the Covid-19 pandemic. As many as $43 \%$ of respondents stated that they were not at all disturbed by the fact that the simultaneous regional elections this time were held during the Covid-19 pandemic. This means that respondents in this category do not differentiate between the Pilkada that will be held at the end of this year from the Pilkada they have already had. The use of suffrage is the main thing for them. Meanwhile, as many as $33 \%$ of respondents stated that they were somewhat disturbed, but they would still use their voting rights in the implementation of the regional elections later this year.

Do you think the KPUD has provided appropriate health protocols?

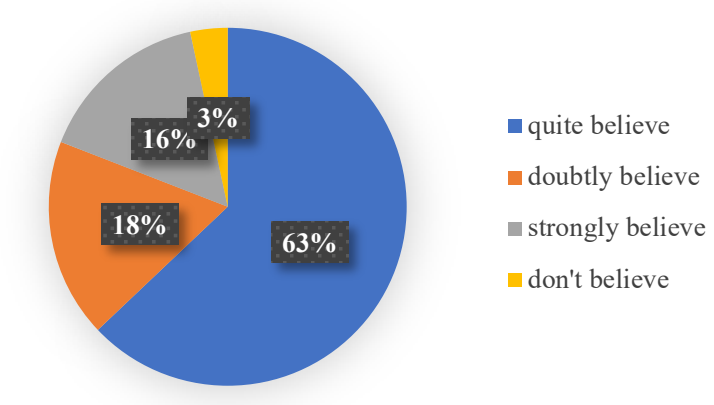

Fig. 2. KPUD has Provided Appropriate Health Protocol.

In terms of health protocols for the Pilkada, it seems that the majority of respondents feel that information on health protocols in the implementation of the simultaneous regional elections is still lacking. A large number of respondents $40 \%$, stated that this information was only minimal. In fact, some $23 \%$ of respondents stated that there was no information at all about health protocols in the implementation of the upcoming simultaneous regional elections. Only $8 \%$ of all respondents stated that the information was very adequate and $29 \%$ of respondents said the information was sufficient. Even though the information is still lacking, 
the majority of respondents believe in the use of health protocols in the upcoming regional elections. As many as $16 \%$ of respondents said they really believed and $63 \%$ said they had enough confidence.

However, the pandemic has big impact on the way people in Central Java think about Pilkada. This survey found that the pandemic has indeed caused $50 \%$ of respondents to become less concerned about the holding of simultaneous local and regional elections. Some $44 \%$ stated that they were not paying attention to the implementation of the upcoming Pilkada, and $6 \%$ stated that they pay less attention to the Pilkada. Meanwhile, the other half of the respondents stated that they still paid enough attention (37\%) and the remaining $13 \%$ stated that they had great attention to the implementation of the Pilkada.

This survey found that respondents' attention to the simultaneous local and regional elections was mainly due to the activities of the prospective candidates. As many as $34 \%$ of respondents said their activities had attracted the respondent's attention. Political party activities only contribute as much as $11 \%$. The efforts made by the KPUD contributed only $22 \%$. It is natural that the activity that attracts the most attention is the activity of the prospective candidate. In some areas, such as the city of Surakarta, the competition for central party leadership (DPP) approval has attracted the attention of not only voters in the city but at the national level, because it involved the president's son who appeared only recently but was able to win the DPP recommendation to compete with PDIP (Indonesian Democratic Party Struggle) flagship. Meanwhile, in several other cities in Central Java, the incumbent that will run again for local leadership, proved to be using social assistance (from central government) to increase their popularity. This happened in Klaten Regency, for example.

Information about these activities is mainly obtained from electronic media, such as television (30\%) and radio (13\%). Another source of information that is quite strong is family and friends, which is as much as $20 \%$. Meanwhile, official government sources such as village heads are only $4 \%$ and RT/RW is only $13 \%$. This reminds us that electronic media is still very important in carrying out its role as a source of information. We still remember how the popularity of a person can soar quickly after receiving electronic media coverage, especially television. President SBY's electability soar 'case proved this.

However, the majority of respondents still need information about who will run for regional head (65\%). This is natural because until the time this survey was conducted, the registration of candidates for regional head had not been carried out yet. Currently the public only knows regional politicians who are interested in running and getting support from certain political parties. Some $15 \%$ of respondents still need knowledge about the date the regional elections will be held simultaneously. It seems that this group of respondents, although they already know about the simultaneous local and regional elections, they do not know yet the exact date of the Pilkada. Perhaps this was due to a change in the election schedule, which was supposed to be held in September, was postponed to December 9. Little is known about the postponement of the implementation of this Pilkada. A number of respondents, $13 \%$, still felt the need to obtain information about voting procedures. Their knowledge of the need to use health protocols prompted them to request that information be given to voters about voting procedures. Only $7 \%$ of respondents need information about the supporting parties that will nominate their candidates in the upcoming Pilkada. This shows that some respondents have enough information already about which parties will compete in the Pilkada process. 
Are you satisfied with the KPUD in educating public about election in pandemic situation?

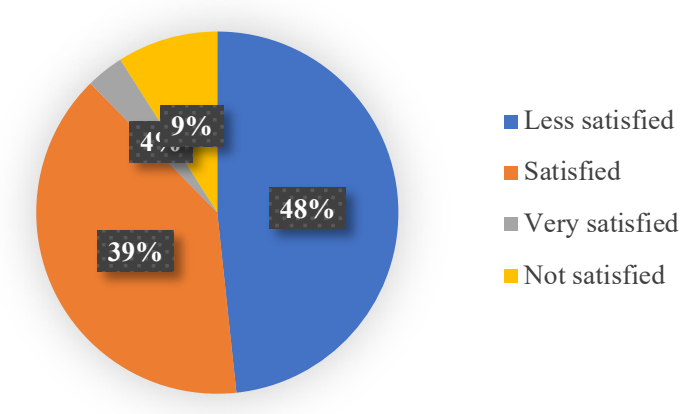

Fig. 3. Being Satisfied with the KPUD in Educating Public about Election in Pandemic Situation.

KPUD performance is measured by two things. The first is performance related to the electoral process in general and the second is related to the role of the KPUD in providing education on the election process during the Covid-19 pandemic. The performance of KPUD in carrying out its role as executor who can guarantee the implementation of the elections honestly and fairly (Jurdil) has received high appreciation from the community. As many as $66 \%$ of respondents said they were satisfied with the performance of the KPUD and $4 \%$ said they were very satisfied. Only $6 \%$ of respondents were dissatisfied, while the remaining $24 \%$ were dissatisfied.

Are you satisfied with KPUD perfomance in assuring that the result of Pilkada will accurate and reflect the will of the people?

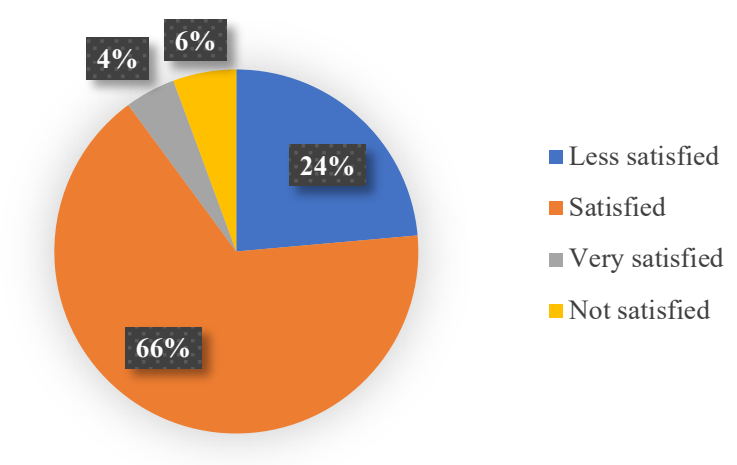

Fig. 4. Being Satisfied with KPUD Performance in Assuring that the Result of Pilkada will Accurate and Reflect the will of the People.

The independence of the KPUD in carrying out its role as election organizer that is free from any political pressure also received high appreciation from respondents. The majority of respondents said they were satisfied with the performance of the KPUD. The majority of respondents, $65 \%$ were satisfied and $9 \%$ were very satisfied. Meanwhile, $21 \%$ and 5\% were dissatisfied. However, when asked about the performance of the KPUD during the Covid-19 
pandemic, the majority of respondents said they were not satisfied, namely $48 \%$ were not satisfied and $9 \%$ were less satisfied. While the number of respondents who were satisfied was $39 \%$ and $4 \%$ were very satisfied. Likewise, the majority of respondents were dissatisfied with the KPUD's performance in preparing health protocols in the implementation of the elections. The majority of respondents expressed dissatisfaction, namely $48 \%$ and $9 \%$ very dissatisfied. Meanwhile, $42 \%$ were satisfied and $1 \%$ were very satisfied. Here we see that there are divided views of respondents towards the KPUD. The routine work carried out by the KPUD has received appreciation because so far respondents have felt that the KPUD has always succeeded in carrying out its duties properly. However, with regard to the implementation of the regional elections during the Covid-19 pandemic, it seems that respondents are still doubtful. But if we look at the percentage of respondents' satisfaction with the KPUD in the electoral performance which reached above $70 \%$, the performance of the KPUD in handling the elections during the Covid-19 pandemic was still within acceptable limits. The ratio of satisfied and dissatisfied respondents is not very significant, namely $57 \%$ : $43 \%$. It can be said that the overall performance of the KPUD has been assessed as good by respondents, although there are still deficiencies in providing outreach on the implementation of the elections during the Covid-19 pandemic.

Do you think it safe to vote in the upcoming Pilkada?

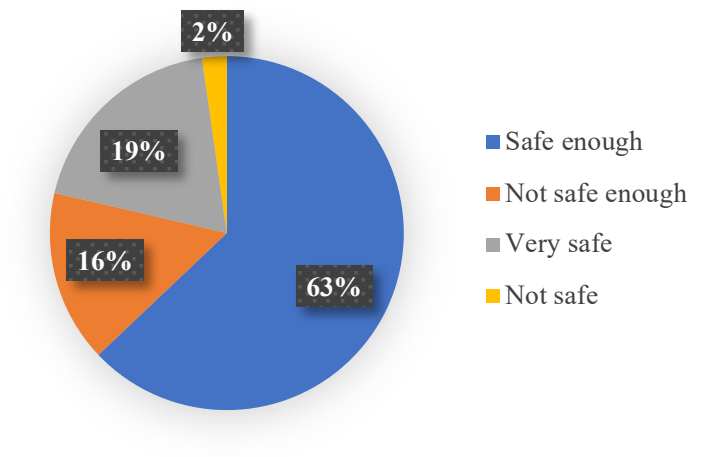

Fig. 5. Thinking that it is Safe to Vote in Upcoming Pilkada.

The performance of the KPUD is considered good, it can also be seen from respondents' statements that $63 \%$ of them feel quite safe and $19 \%$ very safe. Besides that, the majority of respondents also felt that they were not worried about voting in simultaneous local and regional elections during the Covid-19 pandemic. As many as 43 respondents felt there was nothing to worry about, while $44 \%$ felt a little worried but would still vote at the time of the upcoming local and regional elections.

\subsection{The Basis for Voting Local Leaders during the Covid-19 Pandemic}

Basically, the main consideration for giving a vote in the upcoming local and regional elections is the vision and mission of the candidates, namely $61 \%$ followed by popularity as much as $25 \%$, after that money politics is as much as $7 \%$ and supporting parties as much as only $2 \%$. It is interesting to note that the respondents' answers are basically in line with the research of Sulistiyanto and Erb [3], candidate performance is the main concern of 
voters. Observers can breathe somewhat with relief that the considerations for voting are not fundamentally money politics but the vision and mission of the candidates and their popularity. Of course, the opposite can occur when the implementation of the upcoming elections the economic situation declines sharply because the country is experiencing a recession, for example. But we certainly do not expect that. If the economic situation is under control, at least it is still like this, it is likely that the vision and mission and popularity of the candidates will act as guides in voting. Rationalism in voters has been noted by Mietzner [4] who documented that hundreds of regional heads were not elected again when they were unable to provide good public services or were corrupt.

Respondents also rejected the assumption that they would vote to candidates nominated by the winning party in the national election. Even if that happens the reason is not because of the party but rather the performance of the candidate, that was the opinion of $51 \%$ of respondents. Some $26 \%$ stated that the national government party had nothing to do with the Pilkada. It can be proven that many of the combined parties supporting the candidates in the Pilkada are a mixture of the winning national election party and the opposition party. So, it is true that the candidacy in the Pilkada is truly not ideological, and more pragmatic in nature. Concern over the existence of an anti-incumbency movement such as in India [6] should not be alarmed for the same reason. This follows voters will not punish regional heads by not vote them because of the failure of the national government to deal with the pandemic.

\section{Conclusion}

a) Knowledge and Awareness about Pilkada in the Covid-19 pandemic are the variables that most need to be of concern to the KPUD because the public still has a low understanding of how health protocols are implemented. However, the community feels safe to go to the election venue. They will still go to the polling station and give them their vote, even though some people are quite worried about the pandemic situation.

b) The KPUD's performance variables also need attention even though they show good results. This is even more important because the voting community in Central Java has a lot of trust in the KPUD as an independent and Jurdil election organizer. Information about health protocols in the elections is obtained by the public, especially from prospective candidates. Therefore, the KPUD is expected to be more active in seeking breakthroughs to be able to provide education to the public about health protocols in the upcoming Pilkada.

c) The reason for choosing leader variable, the results were quite positive. In general, the public agrees to have a leader candidate who has a vision and mission that they agree with, not a candidate nominated by the winning party for the national election, although candidates with an interesting vision and mission may come from the winning national election party. This also eliminates fears of an anti-incumbency movement such as in India.

\section{References}

[1] M. Kaase, "Is there personalization in politics? Candidates and voting behavior in Germany," Int. Polit. Sci. Rev., vol. 15, no. 3, pp. 211-230, 1994.

[2] H. Kitschelt, "Formation of party cleavages in post-communist democracies: Theoretical propositions," Party Polit., vol. 1, no. 4, pp. 447-472, 1995. 
[3] P. Sulistiyanto and M. Erb, "Indonesia and the Quest for 'Democracy," Deep. Democr. Indones., pp. 1-37, 2009.

[4] M. Mietzner, "Indonesia's direct elections: Empowering the electorate or entrenching the New Order oligarchy," soeharto's new Order its Leg., p. 173, 2010.

[5] G. Van Klinken, "Patronage democracy in provincial Indonesia," in Rethinking popular representation, Springer, 2009, pp. 141-159.

[6] N. Ravishankar, "The cost of ruling: Anti-incumbency in elections," Econ. Polit. Wkly., pp. 92 98, 2009. 